\title{
Serum Matrix Metalloproteinase-8 and -9 Levels in Disseminated Lyme Borreliosis with Special Reference to Arthritis
}

\author{
Anneli Lauhio ${ }^{1,2}$, Jarmo Oksi ${ }^{3}$, Taina Tervahartiala ${ }^{4}$, Jukka Hytönen ${ }^{5}$, Anne Pitkäranta ${ }^{6,7}$, and $\underline{\text { Timo Sorsa }}^{4,8^{*}}$ \\ ${ }^{1}$ Division of Infectious Diseases, Department of Medicine, Helsinki University Central Hospital, 00029, Helsinki, \\ Finland \\ ${ }^{2}$ Department of Medicine, University of Helsinki, 00014, Helsinki, Finland \\ ${ }^{3}$ Department of Medicine, Turku University Hospital, 20014, Turku, Finland \\ ${ }^{4}$ Department of Dentistry, Biomedicum Helsinki, P.O.BOX 63, 00014, Helsinki, Finland \\ ${ }^{5}$ Department of Medical Microbiology and Immunology, University of Turku, 20014, Turku, Finland \\ ${ }^{6}$ Department of Otorhinolaryngology and Head and Neck Surgery, Department of Surgery, Helsinki University \\ Central Hospital, 00029, Helsinki, Finland \\ ${ }^{7}$ Department of Surgery, University of Helsinki, 00014, Helsinki, Finland \\ ${ }^{8}$ Department of Oral and Maxillofacial Diseases, Department of Surgery, Helsinki University Central Hospital, \\ 00029, Helsinki, Finland
}

*Corresponding author: Department of Oral and Maxillofacial Diseases, Biomedicum Helsinki, PO Box 63 (Haartmaninkatu 8), Fin-00014 University of Helsinki, Finland, tel: +358 50 4151327, fax: +358 919125371 , email: timo.sorsa@helsinki.fi

doi:10.5618/bio.2012.v2.n1.7 || Received: 21-08-2012, Accepted: 30-08-2012, Available online: 02-10-2012

\begin{abstract}
Recent evidence suggests that matrix metalloproteinases (MMPs) are involved in pathogenesis of Lyme borreliosis (LB). We studied serum levels of MMP-8 and MMP-9 in disseminated LB patients with special reference to arthritis.

Serum MMP-8 and-9 levels were analyzed by enzyme-linked immunoabsorbent assay from 110 patients from our previous multicenter, prospective study. Serum samples were taken before betalactam antibiotic treatment at study entry and after antibiotic treatment, at 1 year follow-up.
\end{abstract}

Among disseminated LB patients $(n=110)$ mean ( \pm SEM) serum MMP-8 and -9 levels $(\mathrm{ng} / \mathrm{ml})$ at study entry were statistically significantly higher than at 1 year follow-up $(28.0 \pm 1.9$ versus $23.1 \pm 1.6, P=$ $\mathbf{0 . 0 3 1 3}$ and $398.0 \pm 22.7$ vs. $334.3 \pm 23.6, P=0.0219$, respectively). Among Lyme arthritis (LA) patients (n = 34) at study entry serum MMP-8, but not MMP-9, levels decreased significantly when compared to serum levels of those at 1 year follow-up $(35.7 \pm 4.4$ vs. $22.4 \pm 2.3, P=0.0093$ and $398.6 \pm 44.1$ vs. $297.8 \pm$ 40.3, $P=0.0505$, respectively). The mean $( \pm$ SEM) serum levels $(\mathrm{ng} / \mathrm{ml})$ of MMP-8 were significantly higher after betalactam antibiotic treatment at 1 year follow-up among antibiotic resistant LA patients with poor response than among those LA patients who were totally recovered $(32.8 \pm 6.4 \mathrm{vs}$. $20.1 \pm 2.3, P=0.0376)$. In contrast, the mean $( \pm$ SEM) serum levels (ng/ml) of MMP-9 of antibiotic resistant $L A$ patients showed no statistical significant difference when compared to those LA patients who were totally recovered at 1 year follow-up (297.8 \pm 40.3 vs. 396.8 \pm 93.9, $P=0.80)$.

In conclusion, our results suggest that serum MMP-8 levels are excessively upregulated in disseminated LB contributing to inflammatory response, and related to persistent joint symptoms. This novel finding may offer in the future new laboratory possibilities to diagnose patients with persistent symptoms after betalactam antibiotic treatment. In addition the present findings suggest that to improve the outcome of disseminated borreliosis, the therapy of disseminated LB should include MMP-8 inhibitor such as doxycycline, possibly in combination therapy such as a combination of ceftriaxone and doxycycline. 
Keywords: Matrix Metalloproteinase; Matrix Metalloproteinase-8; MMP; MMP-8; MMP-inhibitor; Doxycycline; Disseminated Lyme Borreliosis.

$\begin{array}{ll}\text { Abbreviations } & \\ \text { B. burgdorferi } & \text { Borrelia burgdorferi } \\ \text { CMT } & \text { Chemically modified tetracyclines } \\ \text { ELISA } & \text { Enzyme-linked immunoabsorbent assay } \\ \text { EM } & \text { Erythema migrans } \\ \text { HNE } & \text { Neutrophil elastase } \\ \text { LA } & \text { Lyme arthritis } \\ \text { LB } & \text { Lyme borreliosis } \\ \text { MMP } & \text { Matrix metalloproteinase } \\ \text { MMP-1 } & \text { Matrix metalloproteinase-1 } \\ \text { MMP-2 } & \text { Matrix metalloproteinase-2 } \\ \text { MMP-3 } & \text { Matrix metalloproteinase-3 } \\ \text { MMP-8 } & \text { Matrix metalloproteinase-8 } \\ \text { MMP-9 } & \text { Matrix metalloproteinase-9 } \\ \text { MMP-10 } & \text { Matrix metalloproteinase-10 } \\ \text { MMP-13 } & \text { Matrix metalloproteinase-13 } \\ \text { MMP-19 } & \text { Matrix metalloproteinase-19 } \\ \text { MPO } & \text { Myeloperoxidase } \\ \text { SEM } & \text { Standard error of mean } \\ \text { VAS } & \text { Visual analog scale } \\ & \end{array}$

\section{Introduction}

Lyme disease is an infection caused by a tick-borne spirochete, Borrelia burgdorferi [1]. After tick bite $B$. burgdorferi spreads in the skin to form Erythema migrans (EM) lesions and then disseminates to other organs. Matrix metalloproteinases (MMPs) are induced by host cells in response to B. burgdorferi [2]. It has been suggested that MMPs may play a role in the pathogenesis of borrelia infection [2,3]. The MMP upregulation may play a role in the dissemination of the organism through extracellular matrix tissues resulting in the destructive pathology [3]. MMP-9 (matrix metalloproteinase-9) has been identified in the cerebrospinal fluid of patients with neuroborreliosis [4]. MMP-9 has been shown to be selectively upregulated in the erythema migrans skin lesions of patients with acute Lyme disease [5]. MMP-9 levels were markedly elevated in serum from patients with acute Lyme disease suggesting that bacterial induction of host proteases may be involved in the dissemination of B. burgdorferi [5]. However, recent data does not support the view that MMPs contribute to the dissemination of borreliosis [6].
The cause of persistent joint symptoms in patients with Lyme borreliosis (LB) who have received standard antibiotic therapy remains an area of debate [7-10]. MMP-1, MMP-3, MMP-8 and -9 have been found in synovial fluid of Lyme arthritis (LA) patients [7]. Different MMPs (MMP-1, 2, -3,-10, -13, and -19) have been shown to be induced in different ways in human and murine LA [3, 11]. Lin and colleagues [7] found that the levels of synovial MMPs, also MMP-8, were significantly higher in antibiotic treatment resistant patients. However, to our knowledge serum levels of MMP-8 has not been studied previously in disseminated LB. We set up this work to study the serum levels of MMP-8 and -9 and their oxidative and proteolytic regulators, myeloperoxidase (MPO) and neutrophil elastase (HNE) respectively, in disseminated LB with special reference to arthritis before betalactamantimicrobial chemotherapy and after betalactamantibiotic treatment, at 1 year follow-up.

\section{Patients and methods}

2.1. Patients and study design. This study is a part of our previous study, which was a prospective, multicentre study of disseminated LB in Finland concerning the treatment with betalactam antibiotics (three weeks ceftriaxone followed placebo controlled amoxicillin for 100 days) and outcome [12]. 110 patients of that study had consent and serum samples taken for analysis of MMP and their regulators. Serum samples for MMP and their regulators analysis were taken at entry to study as well at 1 year follow-up. The clinical response after betalactam antibiotics was verified by VAS (visual analog scale) as described earlier in our work [12]. Good response is defined as LA patient having no symptoms and signs at 1 year followup measured by VAS (visual analog scale) and respectively poor response is defined as LA patients having symptoms and signs according to VAS scale at 1 year follow-up. The study protocol was approved by the local Ethical Committee. Patients gave a written informed consent to the study.

2.2. Enzyme-linked immunoabsorbent assay (ELISA). Serum levels of MMP-8, -and -9 as well as MPO and HNE were analyzed by an enzyme-linked immunoabsorbent assay (ELISA) as described earlier $[13,14]$.

2.3. Statistics. Data were analyzed by using GraphPad Prism version 4.0 (GraphPad Inc, San Diego, California, USA). Data of two groups were compared by the paired t-test, Willcoxon rank sum test or unpaired t-test. The results are presented as mean $( \pm$ SEM) or as median (25\%-75\% percentile). A P-value less than 0.05 was considered statistically significant. 


\section{Results}

Among disseminated LB patients $(\mathrm{n}=110)$ mean $( \pm$ SEM) serum MMP-8 levels $(\mathrm{ng} / \mathrm{ml})$ at study entry were statistically significantly higher than at 1 year follow-up $(28.0 \pm 1.9$ versus $23.1 \pm 1.6, \mathrm{P}=0.0313)($ Fig. 1). Mean ( \pm SEM) serum MMP-9 levels $(\mathrm{ng} / \mathrm{ml})$ of the patients with disseminated LB, were at study entry statistically significantly higher than at 1 year follow-up among disseminated LB patients $(\mathrm{n}=110)(398.0 \pm 22.7$ vs. $334.3 \pm 23.6, \mathrm{P}=0.0219)$ (Fig.2). Median (25\% $75 \%$ percentile) serum MPO $(\mathrm{ng} / \mathrm{ml})$ and $\mathrm{HNE}(\mathrm{ng} / \mathrm{ml})$ of the disseminated LB patients $(\mathrm{n}=110)$ at study entry when compared to those at recovery (1 year) showed no statistically significant difference (Table 1).

Mean serum ( \pm SEM) MMP-8 levels $(\mathrm{ng} / \mathrm{ml}$ ) of patients with LA $(n=34)$ decreased statistically significantly when compared of the levels at study entry to those at 1 year follow-up (35.7 \pm 4.4 vs. $22.4 \pm 2.3$, P $=0.0093)($ Fig.3a). In contrast, mean $( \pm$ SEM) serum MMP-9 levels $(\mathrm{ng} / \mathrm{ml})$ of LA patients $(\mathrm{n}=34)$ decreased, but not statistically significantly when compared the serum level of the patients at study entry to those at 1 year follow-up $(398.6 \pm 44.1$ vs. $297.8 \pm$ $40.3, \mathrm{P}=0.0505)$ (Fig.3b).

The mean $( \pm$ SEM) serum levels $(\mathrm{ng} / \mathrm{ml})$ of MMP-8 were significantly higher after betalactam antibiotic treatment at 1 year follow-up among antibiotic resistant LA patients with poor response than among those LA patients who were totally recovered ( $32.8 \pm 6.4$ vs. 20.1 $\pm 2.3, \mathrm{P}=0.0376)($ Fig.4a). The mean $( \pm$ SEM) serum levels (ng/ml) of MMP-9 of antibiotic resistant LA patients showed no statistical significant difference when compared to those LA patients who were totally recovered at 1 year follow-up (297.8 \pm 40.3 vs. $396.8 \pm$ 93.9, $\mathrm{P}=0.80)($ Fig.4b).

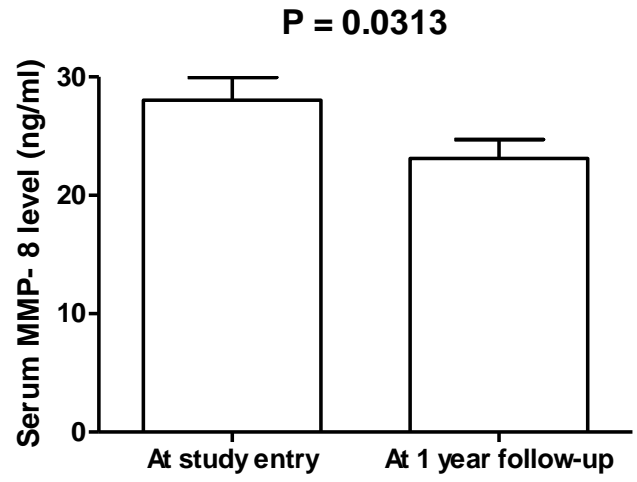

Figure 1. Mean ( \pm SEM) serum MMP-8 levels $(\mathrm{ng} / \mathrm{ml})$ among disseminated LB patients $(\mathrm{n}=110)$ at study entry were significantly higher $(\mathrm{P}=0.0313)$ than at 1 year follow-up.

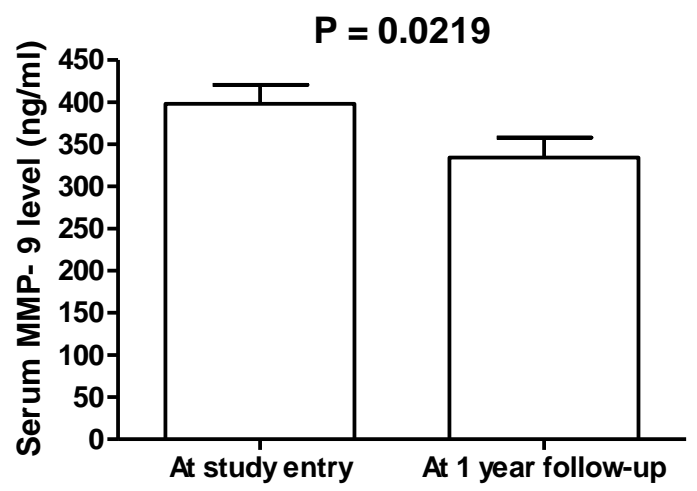

Figure 2. Mean ( \pm SEM) serum MMP-9 levels $(\mathrm{ng} / \mathrm{ml})$ at study entry were significantly higher $(\mathrm{P}=0.0219)$ than at 1 year follow-up among disseminated LB patients $(\mathrm{n}=110)$.

Table 1. Serum MPO and HNE of disseminated LB patients $(n=110)$ at study entry and at 1 year follow-up.

\begin{tabular}{lccc}
\hline \multicolumn{4}{c}{ Disseminated LB patients $(\mathbf{n}=\mathbf{1 1 0})$} \\
\hline & At study entry & At 1 year follow-up & Statistical significance \\
Serum MPO $(\mathrm{ng} / \mathrm{ml})$ & $118.0(63.78-210.1)$ & $88.49(51.35-222.3)$ & 0.0657 \\
Serum HNE $(\mathrm{ng} / \mathrm{ml})$ & $253.3(156.9-382.1)$ & $212.8(143.6-327.3)$ & 0.0506 \\
\hline
\end{tabular}

$\mathrm{MPO}=$ myeloperoxidase $; \mathrm{HNE}=$ human neutrophil elastase $;$ Expressed as median $(25 \%-75 \%$ percentile $)$. 
(a)

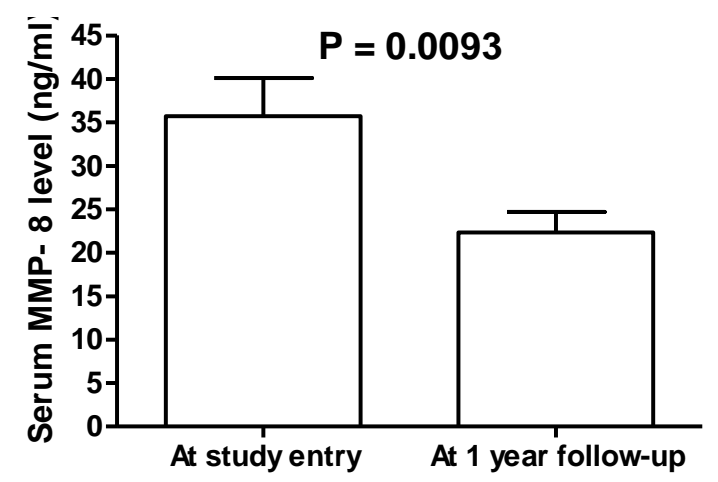

(b)

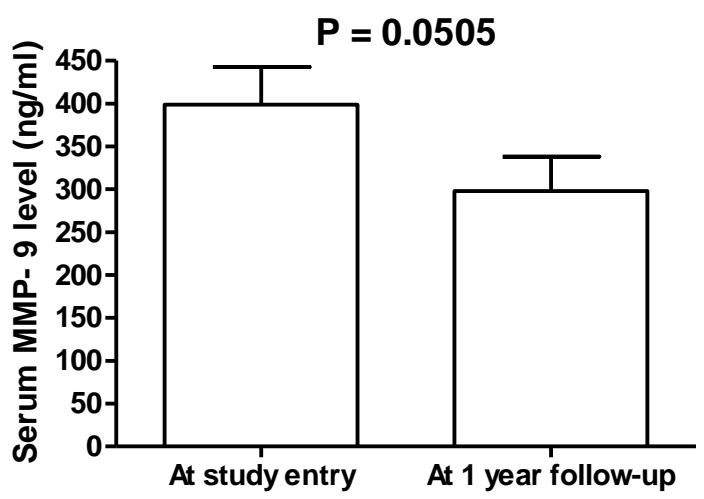

Figure 3. (a) Mean ( \pm SEM) serum MMP-8 levels $(\mathrm{ng} / \mathrm{ml})$ of patients with LA $(\mathrm{n}=34)$ decreased significantly $(\mathrm{P}=0.0093)$ when compared to the serum MMP-8 levels (ng/ml) of LA patients at 1 year followup. (b) Mean ( \pm SEM) serum MMP-9 levels ( $\mathrm{ng} / \mathrm{ml})$ of LA patients $(\mathrm{n}=34)$ decreased, but not significantly $(\mathrm{P}$ $=0.0505)$ when compared the serum levels of the patients at study entry to those at 1year follow-up.

\section{Discussion}

We demonstrated that serum MMP-8 and MMP-9 levels were significantly higher at study entry than at 1 year follow-up among disseminated LB patients $(\mathrm{n}=110)$. In contrast, serum MPO and HNE levels of the disseminated LB patients at study entry when compared to those at 1 year follow-up showed no statistical significant differences. These findings suggest that excessive upregulation of both MMP-8 and MMP-9 in serum of disseminated LB patients before antibiotic therapy contributes to host inflammatory response indicating their important role in the pathogenesis of disseminated LB.

We further found that among LA patients serum MMP-8 levels decreased significantly when compared the serum MMP-8 level of the patients at study entry to those at 1 year follow-up. Additionally serum MMP-8 (a)

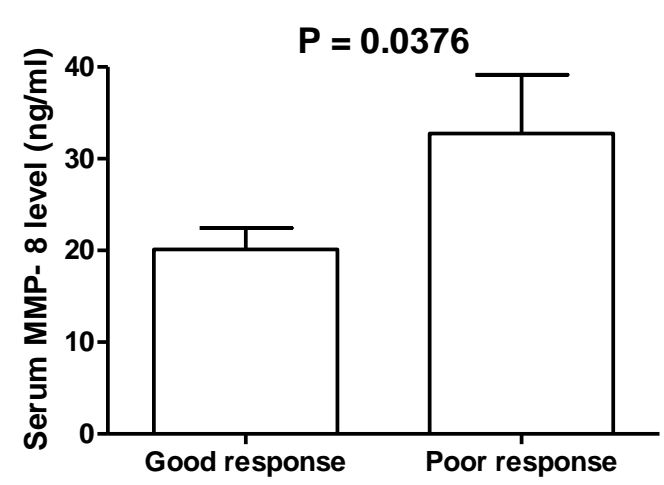

(b)

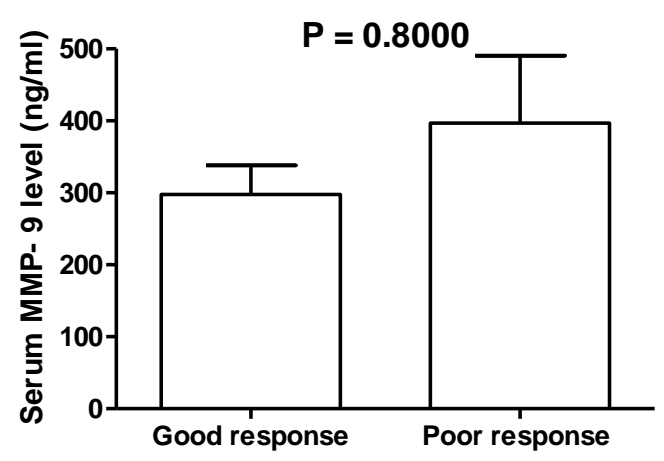

Figure 4. (a) Good response is defined as LA patient having no symptoms and signs at 1 year follow-up measured by VAS (visual analog scale) and respectively poor response is defined as LA patients having symptoms and signs according to VAS scale at 1 year follow-up. (a) Mean ( \pm SEM) MMP-8 levels $(\mathrm{ng} / \mathrm{ml})$ among LA patients $(\mathrm{n}=34)$ with good response is significantly higher than among those LA patients with poor response at 1 year follow-up; $\mathrm{P}=0.0376$. (b) Mean $( \pm$ SEM) MMP- 9 levels $(\mathrm{ng} / \mathrm{ml})$ of LA patients $(\mathrm{n}=34)$ with good and poor response at year follow-up, showed no significant difference; $\mathrm{P}=0.8000$.

levels were significantly higher after antibiotic treatment at 1 year follow-up among those patients who had poor response to given betalactam antibiotic treatment than among those LA patients who had good response and were totally recovered at 1 year follow-up. The present findings demonstrating the upregulation of serum MMP8 levels among betalactam antibiotic resistant patients is in agreement with and further extend previous results by Lin and co-workers [7] demonstrating that in antibiotic treatment resistant LA patients the synovial fluid MMP8 levels were significantly higher than among patients with good response. We also found that serum MMP-9 levels of LA patients decreased, but not statistically significantly when compared the levels at study entry to those at 1 year follow-up. The results of this work 
showing that up-regulation of MMP-8 is associated with poor outcome, suggest that inflammation persists in disseminated LB patients who are not fully recovered after betalactam antibiotics.

$\mathrm{Hu}$ and co-workers [11] studied the involvement of MMPs in cartilage and bone erosions in LA. They examined synovial fluid from patients with LA for MMP-2, MMP-3 and MMP-9. MMPs were identified in the synovial fluids from patients with LA and these were induced from cartilage tissue by the presence of Borrelia burgdorferi. Cartilage destruction was measured by significant increase of glycosaminoglycan (GAG) and hydroxyproline release. The MMP inhibitor batimastat significantly reduced the GAG and hydroxyproline release and completely inhibited the collagen degradation. The authors concluded that inhibition of MMPs prevents B. burgdorferi-induced cartilage degradation. These findings also support the view that the therapy of disseminated LB should include MMP-inhibitor. The results of the present work demonstrating that upregulation of MMP-8 is associated with poor outcome further suggest that the therapy of disseminated LB should include also MMP-8 inhibitor. Doxycycline and other tetracycline group of antibiotics such as lymecycline have been shown to act as MMP-8 inhibitor and down-regulator by several mechanisms both in vitro and in vivo [15-20]. On the basis of the present results together with findings by $\mathrm{Hu}$ and coworkers [11] we suggest that doxycycline as MMP-8 inhibitor should be included in the treatment of disseminated LB.

There is no internationally accepted way to treat those disseminated LB patients, who have persisting symptoms after antibiotic treatment [8-10]. In a Finnish multicenter, prospective study regarding the treatment of disseminated LB it was found that by using betalactam antibiotics, the cure rate was quite high, but there still were patients, who were not totally recovered at 1 year follow-up [12]. The results of the present work showing that among these patients suffering from persistent joint symptoms after betalactam antibiotic treatment high serum MMP-8 was associated with poor outcome suggest that the treatment of the patients having persisting symptoms after betalactam antibiotics should include doxycycline as an MMP-8 inhibitor. It is likely that due to rebound effect a short one week course will not be sufficient [21], but instead a longer treatment with doxycycline would be needed [15, 18, 19]. In addition, the results of this work suggest that serum MMP-8 assessment could possibly be useful in the monitoring of the effectiveness of the therapy [22]. One possibility could also be that by using MMP-8 measurement, the subgroup of the patients, who need for prolonged doxycycline therapy after for example intravenous ceftriaxone, could be found. However, more studies concerning this topic are needed.

Chlamydia arthritis, one form of reactive arthritis, is like Lyme arthritis an infectious associated arthritis, where some patients suffer from chronic sequelae. In a study by Lauhio and co-workers [23] it was shown that three month lymecycline has a favorable effect in acute chlamydia arthritis and recently it was demonstrated that six months combination therapy of two antibiotics is efficient in chronic chlamydia arthritis [24]. Single antibiotic therapy with doxycycline in disseminated LB has shown relatively low cure rates, as has been shown in studies by Borg and colleagues [25], Orgnic and coworkers [26] as well as by Ljøstad and co-workers [27]. Thus, one possibility to achieve better cure rates could be to use a combination therapy of doxycycline and intravenous ceftriaxone, at least to the subgroup of patients with persistent symptoms after ceftriaxone treatment. One possibility to improve the outcome of disseminated LB could be to use combination therapy for those patients, who are not fully recovered after ceftriaxone treatment. In the future, instead of doxycycline, chemically modified tetracyclines (CMTs) with MMP-8 inhibitory capacity could also be one possibility in combination with ceftriaxone [22]. More clinical studies concerning the combination therapy including MMP-8 inhibitor are needed to get better treatment strategies for disseminated LB.

In addition, Yrjänäinen and co-workers [28] has shown that Borrelia burgdorferi-infected and ceftriaxone-treated mice have viable spirochetes in their body, since immunosuppressive treatment allows $B$. burgdorferi to be detected by culture. In a subsequent study the niche of persisting $B$. burgdorferi in ceftriaxone-treated mice was obviously the joint or a tissue adjacent to the joint [29]. Also these recent animal model studies supports the view that a combination therapy could possibly lead to better outcome than single antibiotic therapy, at least to some subgroup of patients with disseminated LB.

\section{Conclusions}

The results of the present work suggest that serum MMP-8 levels are excessively upregulated in disseminated LB contributing to inflammatory response, and related to persistent joint symptoms. This novel finding may offer in the future new laboratory possibilities to diagnose patients with persistent symptoms after betalactam antibiotic treatment. In addition, we conclude that to improve the outcome, the therapy of disseminated LB should include MMP-8 
inhibitor such as doxycycline, possibly in combination therapy. Further studies of this topic are needed.

\section{Acknowledgements}

The authors thank Maiju Kivistö for secretarial work. This study was supported by grants from the Academy of Finland and Helsinki University Central Hospital Research Funds (EVO).

Conflict of interest statement: none declared.

\section{References}

[1] Steere, A. C. Lyme disease. N. Engl. J. Med. 2001, 345, 115-125. http://dx.doi.org/10.1056/NEJM200107123450207

[2] Gebbia, J. A.; Coleman, J. L.; Benach, J. L. Borrelia spirochetes upregulate release and activation of matrix metalloproteinase gelatinase B (MMP-9) and collagenase 1 (MMP-1) in human cells. Infect. Immun. 2001, 69, 456-462. http://dx.doi.org/10.1128/IAI.69.1.456-462.2001

[3] Behera, A. K.; Hildebrand, E.; Scagliotti, J.; Steere, A. C.; Hu, L. T. Induction of host matrix metalloproteinases by Borrelia burgdorferi differs in human and murine lyme arthritis. Infect. Immun. 2005, 73, 126-134. http://dx.doi.org/10.1128/IAI.73.1.126$\underline{134.2005}$

[4] Kirchner, A.; Koedel, U.; Fingerle, V.; Paul, R.; Wilske, B.; Pfister, H. W. Upregulation of matrix metalloproteinase-9 in the cerebrospinal fluid of patients with acute Lyme neuroborreliosis. J. Neurol. Neurosurg. Psychiatry 2000, 68, 368-371. http://dx.doi.org/10.1136/innp.68.3.368

[5] Zhao, Z.; Fleming, R.; McCloud, B.; Klempner, M. S. CD14 mediates cross talk between mononuclear cells and fibroblasts for upregulation of matrix metalloproteinase 9 by Borrelia burgdorferi. Infect. Immun. 2007, 75, 3062-3069. http://dx.doi.org/10.1128/IAI.00202-07

[6] Heilpern, A. J.; Wertheim, W.; He, J.; Perides, G.; Bronson, R.; Hu, L. T. Matrix metalloproteinase 9 plays a key role in lyme arthritis but not in dissemination of Borrelia burgdorferi. Infect. Immun. 2009, 77, 2643-2649. http://dx.doi.org/10.1128/IAI.00214-09

[7] Lin, B.; Kidder, J. M.; Noring, R.; Steere, A. C.; Klempner, M. S.; Hu, L. T. Differences in synovial fluid levels of matrix metalloproteinases suggest separate mechanisms of pathogenesis in Lyme arthritis before and after antibiotic treatment. $J$. Infect. Dis. 2001, 184, 174-180. http://dx.doi.org/10.1086/322000
[8] Auwaerter, P. G. Point: Antibiotic therapy is not the answer for patients with persisting symptoms attributable to Lyme disease. Clin. Infect. Dis. 2007, 45, 143-148. http://dx.doi.org/10.1086/518854

[9] Mygland, A.; Ljøstad, U.; Fingerle, V.; Rupprecht, T.; Schmutzhard, E.; Steiner, I. EFNS guidelines on the diagnosis and management of European Lyme neuroborreliosis. Eur. J. Neurol. 2010, 17, 8-16. http://dx.doi.org/10.1111/j.1468-1331.2009.02862.x

[10] O'Connell, S. Lyme borreliosis: current issues in diagnosis and management. Curr. Opin. Infect. Dis. 2010, 23, 231-235. http://dx.doi.org/10.1097/Qco.0b013e32833890e2

[11] Hu, L. T.; Eskildsen, M. A.; Masgala, C.; Steere, A. C.; Arner, E. C.; Pratta, M. A.; Grodzinsky, A. J.; Loening, A.; Perides, G. Host metalloproteinases in Lyme arthritis. Arthritis Rheum. 2001, 44, 1401$1410 . \quad$ http://dx.doi.org/10.1002/15290131(200106)44:6<1401::AID-ART234>3.0.CO;2-S

[12] Oksi, J.; Nikoskelainen, J.; Hiekkanen, H.; Lauhio, A.; Peltomaa, M.; Pitkäranta, A.; Nyman, D.; Granlund, H.; Carlsson, S. A.; Seppälä, I.; Valtonen, V.; Viljanen. M. Duration of antibiotic treatment in disseminated Lyme borreliosis: A double-blind, randomized, placebo-controlled, clinical multicentre study. Eur. J. Clin. Microbiol. Inf. Dis. 2007, 26, 571-581. http://dx.doi.org/10.1007/s10096-007-0340-2

[13] Rautelin, H. I.; Oksanen, A. M.; Veijola, L. I.; Sipponen, P. I.; Tervahartiala, T. I.; Sorsa, T. A.; Lauhio, A. Enhanced systemic matrix metalloproteinase response in Helicobacter pylori gastritis. Ann. Med. 2009, 41, 208-215. http://dx.doi.org/10.1080/07853890802482452

[14] Lauhio, A.; Hästbacka, J.; Pettilä, V.; Tervahartiala, T.; Karlsson, S.; Varpula, T., Varpula, M.; Ruokonen, E.; Sorsa, T.; Kolho, E. Serum MMP-8, -9 and TIMP1 in sepsis: High serum levels of MMP-8 and TIMP-1 are associated with fatal outcome in a multicentre, prospective cohort study. Pharmacol. Res. 2011, 64, 590-594. http://dx.doi.org/10.1016/j.phrs.2011.06.019

[15] Lauhio, A.; Saikku, P.; Salo, T.; Tschesche, H.; Lähdevirta, J.; Sorsa, T. Combination treatment in Chlamydia-triggered reactive arthritis. Comment on the article by Carter et al. Arthritis Rheum. 2011, 63, 305-307. http://dx.doi.org/10.1002/art.30075

[16] Lauhio, A.; Sorsa, T.; Lindy, O.; Suomalainen, K.; Saari, H.; Golub, L. M.; Konttinen, Y. T. The anticollagenolytic potential of lymecycline in the long-term treatment of reactive arthritis. Arthritis Rheum. 1992, 35, 195-198. http://dx.doi.org/10.1002/art.1780350211 
[17] Golub, L. M.; Lee, H. M.; Ryan, M. E.; Giannobile, W. V.; Payne, J.; Sorsa, T. Tetracyclines inhibit connective tissue breakdown by multiple nonantimicrobial mechanisms. Adv. Dent. Res. 1998, 12, 12-26. http://dx.doi.org/10.1177/08959374980120010501

[18] Lauhio, A.; Konttinen, Y. T.; Tschesche, H.; Nordström, D.; Salo, T.; Lähdevirta, J.; Golub, L. M.; Sorsa, T. Reduction of matrix metalloproteinase 8neutrophil collagenase levels during long-term doxycycline treatment of reactive arthritis. Antimicrob. Agents Chemother. 1994, 38, 400-402. http://dx.doi.org/10.1128/AAC.38.2.400

[19] Lauhio, A.; Salo, T.; Ding, Y.; Konttinen, Y. T.; Nordström, D.; Tschesche, H.; Lähdevirta, J.; Golb, L. M.; Sorsa, T. In vivo inhibition of human neutrophil collagenase (MMP-8) activity during long-term combination therapy of doxycycline and nonsteroidal anti-inflammatory drugs (NSAID) in acute reactive arthritis. Clin. Exp. Immunol. 1994, 98, 2128. http://dx.doi.org/10.1111/j.1365-2249.1994.tb06601.x

[20] Golub, L. M.; Lee, H. M.; Stoner, J. A.; Sorsa, T.; Reinhardt, R. A.; Wolff, M. S.; Ryan, M. E.; Nummikoski, P. V.; Payne, J. B. Subantimicrobialdose doxycycline modulates gingival crevicular fluid biomarkers of periodontitis in postmenopausal osteopenic women. J. Periodontol. 2008, 79, 14091418. http://dx.doi.org/10.1902/jop.2008.070623

[21] Lauhio, A.; Salo, T.; Tjäderhane, L.; Lähdevirta, J.; Golub, L. M.; Sorsa, T. Tetracyclines in treatment of rheumatoid arthritis. Lancet 1995, 346, 645-646. http://dx.doi.org/10.1016/S0140-6736(95)91484-6

[22] Sorsa, T.; Tervahartiala, T.; Leppilahti, J.; Hernandez, M.; Gamonal, J.; Tuomainen, A. M.; Lauhio, A.; Pussinen, P.; Mäntylä, P. Collagenase-2 (MMP-8) as a point-of-care biomarker in periodontitis and cardiovascular diseases. Therapeutic response to non-antimicrobial properties of tetracyclines. Pharmacol. Res. 2011, 63, 108-113. http://dx.doi.org/10.1016/j.phrs.2010.10.005

[23] Lauhio, A.; Leirisalo-Repo, M.; Lähdevirta, J.; Saikku, P.; Repo, H. Double-blind, placebo- controlled study of three-month treatment with lymecycline in reactive arthritis, with special reference to Chlamydia arthritis. Arthritis Rheum. 1991, 34, 6-14. http://dx.doi.org/10.1002/art.1780340103

[24] Carter, J. D.; Espinoza, L. R.; Inman, R. D.; Sneed, K. B.; Ricca, L. R.; Vasey, F. B.; Valeriano, J.; Stanich, J. A.; Oszust, C.; Gerard, H.C.; Hudson, A. P. Combination antibiotics as a treatment for chronic Chlamydia-induced reactive arthritis: a double-blind, placebo-controlled, prospective trial. Arthritis Rheum. 2010, 62, 1298-1307. http://dx.doi.org/10.1002/art.27394

[25] Borg, R.; Dotevall, L.; Hagberg, L.; Maraspin, V.; Lotric-Furlan, S.; Cimperman, J.;Strle, F. Intravenious ceftriaxone compared with oral doxycycline for the treatment of Lyme neuroborreliosis. Scand. J. Infect. Dis. 2005, 37, 449454. http://dx.doi.org/10.1080/00365540510027228

[26] Ogrinc, K.; Logar, M.; Lotric-Furlan, S.; Cerar D.; Ruzić-Sabljić, E.; Strle, F. Doxycycline versus ceftriaxone for the treatment of patients with chronic Lyme borreliosis. Wien. Klin. Wochenschr. 2006, 118, 696-701. http://dx.doi.org/10.1007/s00508-006-0698-7

[27] Ljøstad, U.; Skogvoll, E.; Eikeland, R.; Midgard, R.; Skarpaas, T.; Berg, A.; Mygland, A. Oral doxycycline versus intravenous ceftriaxone for European Lyme neuroborreliosis: a multicentre, noninferiority, double-blind, randomised trial. Lancet Neurol. 2008, 7, 690-695. p://dx.doi.org/10.1016/S14744422(08)70119-4

[28] Yrjänäinen, H.; Hytönen, J.; Song, X. Y.; Oksi, J.; Hartiala, K.; Viljanen ,M. K. Anti-tumor necrosis factor- alpha treatment activates Borrelia burgdorferi spirochetes 4 weeks after ceftriaxone treatment in C3H/HE mice. J. Infect. Dis. 2007, 195, 1489-1496. http://dx.doi.org/10.1086/513873

[29] Yrjänäinen, H.; Hytönen, J.; Hartiala, P.; Oksi, J.; Viljanen, M. K. Persistence of borrelial DNA in the joints of Borrelia burgdorferi-infected mice after ceftriaxone treatment. APMIS. 2010, 118, 665-673. http://dx.doi.org/10.1111/j.1600-0463.2010.02615.x 